\section{Saccular aneurysm of left main coronary artery}

A 48-year-old woman with no traditional coronary risk factors, presented to our hospital with a recent anterior ST elevation myocardial infarction which had been thrombolysed, from a local hospital. Her physical examination and routine investigations were unremarkable. A coronary angiogram (figure 1) revealed a saccular aneurysm arising from the left main coronary artery (LMCA). There were no stenotic lesions noted at the aneurysm site or elsewhere. A coronary intravascular ultrasound study demonstrated a wide-mouthed aneurysm in the LMCA measuring $3.5 \times 4.5 \mathrm{~mm}$, with no thrombus within (figure 2 ).

Coronary artery aneurysms, are usually defined as dilatation of a segment of a coronary artery more than 1.5 times the normal size. Morphologically, they may be saccular or fusiform. The most common cause of coronary artery aneurysms is atherosclerosis. Other causes include Kawasaki disease, aortoarteritis or trauma; coronary artery aneurysms can also be mycotic, congenital or idiopathic. The reported incidence is about
$1.65 \%$, while LMCA aneurysms are rarer still with an incidence of $0.1 \%$ in a large angiographic series. ${ }^{1}$ Coronary artery aneurysms are prone to spasm, spontaneous dissection, intraluminal thrombus formation and distal embolisation which could lead to myocardial ischaemia or infarction. Therapy is largely guided by the presence of associated stenotic lesions. Treatment options include anticoagulation, covered stents and surgical options including reconstruction, resection and bypass surgery. ${ }^{2}$

This case highlights the fact that coronary artery aneurysms with intraluminal thrombus, may be an important cause of myocardial infarction. Recognition of this entity is vital, as longterm anticoagulation is essential in preventing future thrombotic events.

\section{Jyothish Vijay, Salman Salahuddin, Ali Faizal}

Department of Cardiology, Malabar Institute of Medical Sciences, Calicut, Kerala, India

Correspondence to Dr Salman Salahuddin, Department of Cardiology, Malabar Institute of Medical Sciences, Calicut, Kerala 673016, India; drsalmans@gmail.com

Contributors JV and SS wrote the manuscript. AF was involved in acquisition of images and critical analysis of the manuscript. All authors approved the final manuscript.

Competing interests None.
Figure 1 Coronary angiography images in the cranial $(A)$ and caudal (B) projections showing a saccular aneurysm arising from the left main coronary artery.
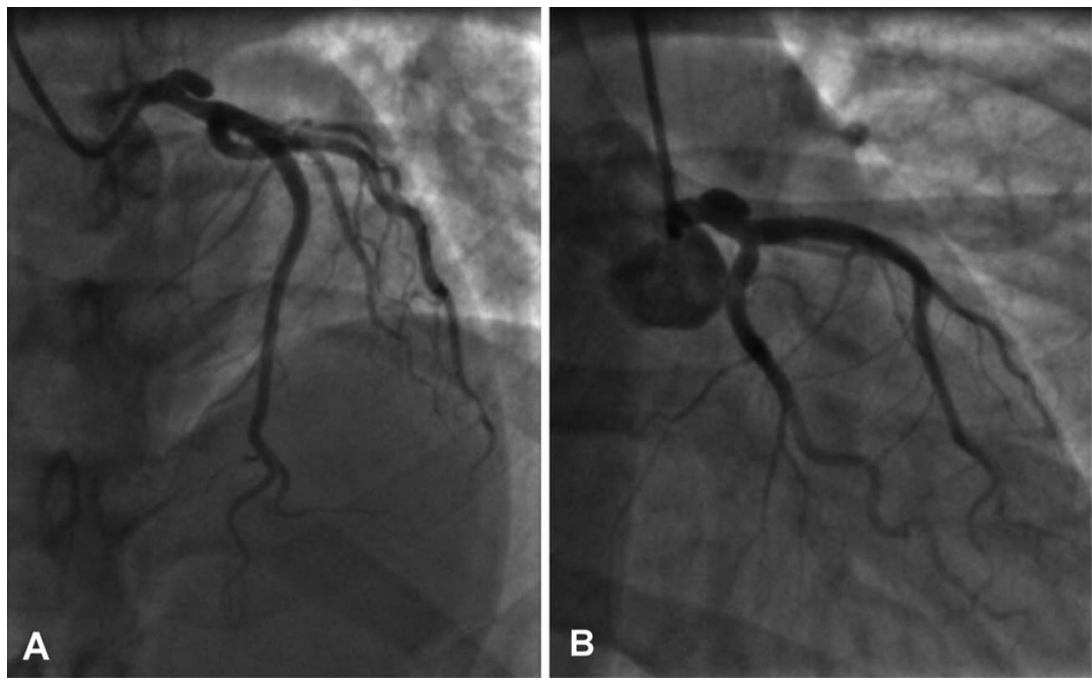

Figure 2 Intravascular ultrasound images of proximal left main coronary artery (LMCA) (A) and distal LMCA with aneurysm (B).
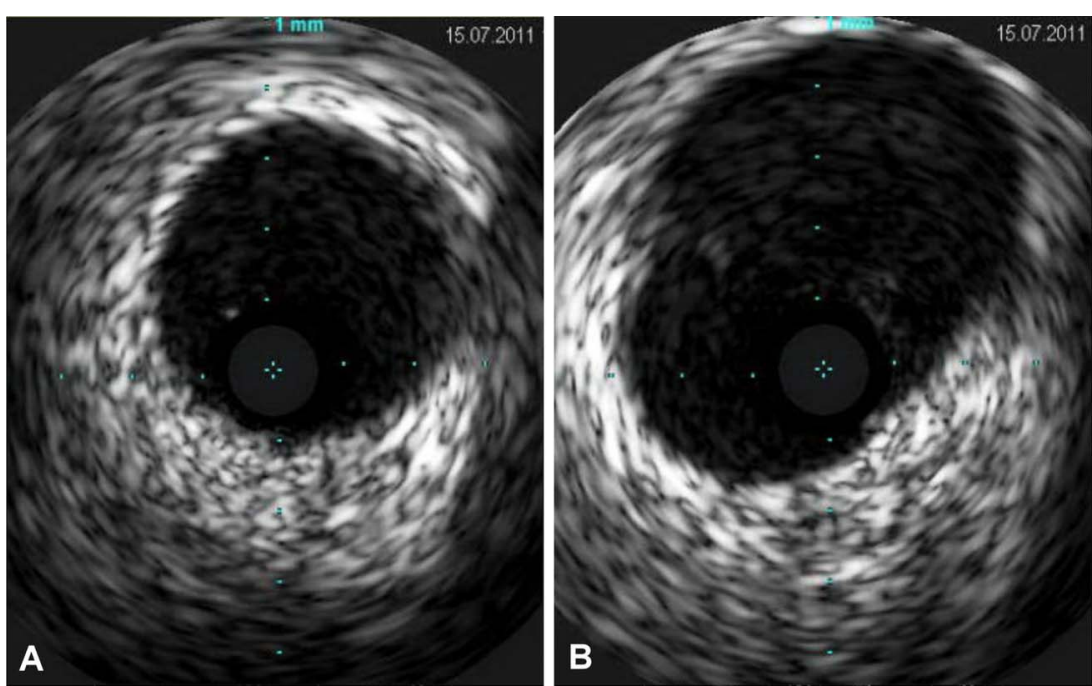
Patient consent Obtained.

Provenance and peer review Not commissioned; internally peer reviewed.

To cite Vijay J, Salahuddin S, Faizal A. Heart Asia Published Online First: [please include Day Month Year] doi:10.1136/heartasia-2013-010260

Heart Asia 2013;0:30-31. doi:10.1136/heartasia-2013-010260

\section{REFERENCES}

1 Topaz 0, DiSciascio G, Crowley MJ, et al. Angiographic features of the left main coronary artery aneurysms. Am J Cardiol 1991;67:1139-42.

2 Everett JE, Burkhart HM. Coronary artery aneurysm: case report. J Cardiothorac Surg 2008;3:1. 